work. ${ }^{2} 3$ Presumably both authors and editors assume that their readers have short memories.

H C BURRY

Wellington Hospital,
Wellington,
New Zealand

P A DIEPpe

Bristol Royal Infirmary,
Bristol BS2 8HW

1 Nanra RS, Chirawong P, Kincaid-Smith P. Renal infection and renal scarring. Melbourne: Mercedes, infection and
$1971: 347$. 1971:347.
Bry HC, Dieppe PA, Bresnihan FB, Brown C.
Br Med 1976;i:613-5.

- Burry HC, Dieppe PA. Br Med f 1976;ii:16-7.

Dieppe PA, Tucker SM, Burry HC, Bresnihan FP. Rheumatol Rehabil 1975;14:226-30. - Burry HC. Ann Rheum Dis 1972;31:65-8. Rherm Dis
1968;27:339-43.

\section{Discrepancy in results from three guaiacum resin tests}

SIR,-The short report by Dr B Feneyrou and others (23 January, p 235) shows clearly the problems involved in occult blood testing when an unrestricted diet is maintained. We have repeatedly pointed out the importance of restricted diet if Fecatest (or Fecatwin Sensitive) (Labsystems Oy, Helsinki, Finland) is used for occult blood testing. ${ }^{12}$ In addition many of the "false-positives" obtained in the study of Feneyrou and others may be due to bleeding from the upper gastrointestinal tract because the sensitive tests detect very well bleeding from this region. ${ }^{3}$

In a recent study measuring bleeding with ${ }^{51} \mathrm{Cr}$-marked erythrocytes after keeping a strict diet, as recommended for Fecatest and Fecatwin Sensitive, the in-vivo results were compared with the in-vitro tests in 35 48-h samples from subjects with colorectal cancer ( 15 patients) and other colon tumours (three) and nine 48-h samples from controls (nine subjects). In the presence of colorectal cancer Fecatest and Fecatwin S were correctly positive in $93 \%$ and $89 \%$, respectively. False-positive results based on actual bleeding measurements (all patients) (bleeding $<2 \mathrm{ml} / 24 \mathrm{~h}$ ) were found in $9 \%$ for Fecatest and $7 \%$ for Fecatwin $\mathrm{S}$ (one subject had eaten large amounts of uncooked salmon, the other had benign tumours in the sigmoid colon or rectum bleeding less than $2 \mathrm{ml} /$ day). Real false-negatives (bleeding $>2 \mathrm{ml}$ $24 \mathrm{~h}$ ) were obtained in only $2 \%$ of the samples (one sample) with both tests. Using the less sensitivetest, Fecatwin (Labsystems), the percentage of true-positives in the colorectal cancer group decreased to $86 \%$. The percentage of falsepositives was the same as for Fecatwin S (7\%) and the percentage false-negatives increased to $4.5 \%$. Thus all Labsystems tests perform well if the diet is restricted. Previous results obtained with Fecatest are in agreement. ${ }^{4}$

In another study, 864 consecutive samples from patients with a suspicion of bleeding maintained on a restricted diet were screened with five guaiac tests. All subjects $(\mathrm{No}=90)$ with obvious clinical signs of active bleeding (anaemia, bleeding-site located, blood vomiting, blood visible in stools were selected out from the total subjects and the results, expressed as percentage true-positive single

test results, are shown in the table. In addition we show the corresponding results for two subgroups representing all subjects with gastric or duodenal ulcers (11 patients) or gastric cancer (six) and all those with colon cancers (three) or ulcerative colitis (seven). For the sensitive tests (Fecatest and Fecatwin S) about $80 \%$ of the upper gastrointestinal bleeding and about $90 \%$ of the colorectal bleeding were detected with a single test. For the non-sensitive tests Fecatwin, Haemoccult (Röhm-Pharma, same as Hemoccult II), and BM-test Hemafecia (Boehringer-Mannheim) 3.5 times more false-negatives were obtained with the samples from patients with colorectal bleeding. Thus the results for Labsystems tests agree well with those obtained in the abovementioned study including actual measurements of the bleeding.

In our opinion the sensitive tests should be used for hospitalised and well motivated outpatients, who can maintain a correct diet and the non-sensitive restricted for use in screening. All subjects should be maintained on a haemoprotein-free diet. No other dietary alterations (for example, addition of roughage) are needed if the sensitive Fecatwin and Fecatwin $S$ tests are used.

H ADLERCREUTZ K LIEWENDAHI P VIRKOLA

\section{Department of Clinical Chemistry SF-00290 Helsinki 29}

IInd Department of Surgery,

Helsinki University Central

Hospital,

SF-00290 Helsinki 29

${ }^{1}$ Adlercreutz H, Liewendahl K, Virkola P. Gastroenterology 1980;79:959-60. $1980 ; 18: 695$

Heinrich HC, Ićagić F. Klin Wochenschr 1980;58: 1283-97. Adlercreutz H, Liewendahl K, Virkola P. Clin Chem
1978;24:756-61.

\section{Methadone produces prolonged} postoperative analgesia

SIR,-The short report from Dr G K Gourlay and others on methadone analgesia (27 February, p 630) states that effective intravenous analgesia requires "expensive infusion pumps." I would like to describe an inexpensive method of accurately infusing smal quantities of fluid using a gravity-operated microbore infusion system.

Using a standard infusion set at a height of $1 \mathrm{~m}$ Uove the infusion site running without restriction through a $3.8-\mathrm{cm}$-long 30 standard wire gauge needle, a flow of $7.5 \mathrm{ml}$ an hour is obtained. Because the flow is unrestricted in the tubing there is a maximum pressure differential across the needle so that reflux of fluid does not occur when the needle is introduced into another intravenous infusion. To ensure this further a short length of wire can be used to suspend the main infusion bottle, say $15 \mathrm{~cm}$ below the gravity-operated microbore infusion system bottle.

A one-way valve can be used in the main infusion

Frequency (\%) of true-positive single tests for occult blood in faeces with various guaiac tests in samples from patients with obvious clinical signs of active bleeding

\begin{tabular}{|c|c|c|c|c|c|}
\hline & $\begin{array}{c}\text { Fecatest, } \\
\text { Labsystems }\end{array}$ & $\begin{array}{c}\text { Fecatest Sensitive, } \\
\text { Labsystems }\end{array}$ & $\begin{array}{l}\text { Fecatwin, } \\
\text { Labsystems }\end{array}$ & $\begin{array}{c}\text { Haemoccult (II), } \\
\text { Röhm-Pharma }\end{array}$ & $\begin{array}{l}\text { BM-test Hemafecia, } \\
\text { Boehringer-Mannheim }\end{array}$ \\
\hline $\begin{array}{l}\text { Total patients }(n=90) \\
\text { Patients with gastric and } \\
\text { duodenal ulcer, or } \\
\text { gastric cancer }(n=\end{array}$ & 81 & 79 & 60 & 56 & 56 \\
\hline $\begin{array}{c}17) \\
\text { Patients }\end{array}$ with colon & 79 & 77 & 62 & 57 & 57 \\
\hline $\begin{array}{l}\text { cancer, or ulcerative } \\
\text { colitis }(n=10)\end{array}$ & 90 & 90 & 65 & 65 & 65 \\
\hline
\end{tabular}

line to ensure that reflux up the main infusion does not occur should the infusion be obstructed for any reason. Subsequent release of the obstruction could then result in a bolus of drug from the gravity-operated microbore infusion system being infused rapidly; a risk shared with expensive infusion pumps, incidentally. The very small gauge of the needle ensures that the only way to vary the rate of the infusion is to alter the pressure in the tubing. Provided a pressure infusor is not used this means that variation in flow is limited by the height that the bottle is above the infusion site and changing the position of the patient. Sitting up the patient may reduce the flow by around $10 \%$, while raising the bottle to the full height of the tubing $(1.25 \mathrm{~m})$ can increase the flow by $25 \%$.

You will appreciate that this system is satisfactory for the continuous infusion of postoperative analgesics where a small variation in flow may be desirable but a guaranteed maximum flow rate is mandatory.

I have used this system with success but have to report that nursing staff mistrust an infusion running at two drops a minute without any need for adjustment. Out of deference to their feelings I now use clockwork syringe pumps, but I report this system since its cheapness and inherent safety should appeal to doctors working in deprived parts of the Third World and NHS.

J M Cundy

Lewisham Hospital,

\section{Cetrimide allergy presenting as} suspected non-accidental injury

SIR,-I am grateful to Dr J S Pegum (6 March, $p$ 746) for his observations on my recent article "Cetrimide allergy presenting as suspected non-accidental injury" (6 February, $p$ 385). His premise that $12 \%$ cetrimide solution is likely to cause an irritant reaction can, however, be refuted. Prior to the experiment on the child, pads soaked in a $12 \%$ solution were worn against the skin by two people (one of them for a week), neither of whom developed any irritation.

The prima facie object of the original test was not to determine allergy but to help determine whether the child's name should be included on the "at-risk" register, hence the use of a $12 \%$ cetrimide solution as made up and used in our hospital.

ICI Ltd, the makers of Cetavlon PC, have asked me to point out that the concentration of cetrimide in their proprietary preparation is $17.5 \%$ solution and not $12 \%$ as stated in the original article.

JOHN K INMAN

Skipton,
North Yorks

Renal failure-dilemmas and

developments

SIR,-Dr Martin S Knapp (20 March, p 847) has provided us with a good review at a time of reorganisation of the hospital service, and renewed interest in the allocation of resources, and two years following the Panorama debacle.

I agree entirely that transplantation should be considered the treatment of choice for mos patients with end-stage renal failure. Un fortunately, this goal is not often achieved because of the continuing shortage of cadaveric organ donors. Since the care of the brain dead donor is well described, ${ }^{1}$ the principal cause 